\title{
A Comparative Study of Split-Root and Bone Removal in the Extraction of Mandibular Impacted Third Molars
}

\author{
Wen-chao Li", Ning Ruan, Guang-hui Lv, Yang Lin, Min-qiang Zhao, Bo-chen Lei, Yi-fu Wang, \\ Wei Zu, Yuan Tian
}

Department of Oral Surgery, Affiliated Hospital of Chifeng College, Chifeng, China

Email address:

nmcflwch21@126.com (Wen-chao Li),nmcfrn21@126.com (Ning Ruan)

\section{To cite this article:}

Wen-chao Li, Ning Ruan, Guang-hui Lv, Yang Lin, Min-qiang Zhao, Bo-chen Lei, Yi-fu Wang, Wei Zu, Yuan Tian. A Comparative Study of Split-Root and Bone Removal in the Extraction of Mandibular Impacted Third Molars. Journal of Surgery. Vol. 4, No. 2, 2016, pp. 8-12. doi: $10.11648 /$ j.js.20160402.11

\begin{abstract}
This paper is aimed to compare the effects of split-root procedures and bone removal procedures in the extraction of mandibular medial vertical impacted third molars. This was a prospective study conducted at the Department of Oral Surgery of the Chifeng College Affiliated Hospital on consecutive patients between January 2015 and December 2015. The study result showed that the operative time of the split-root group was shorter, and the dental root fracture was less than the bone removal group. This study suggested that the short-term outcomes of medial vertical impacted third molar operations (facial swelling, pain and mouth opening) differed depending on the surgical approach.
\end{abstract}

Keywords: Split-Root, Bone Removal, Vertical Impacted Teeth, Third Molar

\section{Introduction}

In early 1966, Archer [1] defined an impacted third molars (ITMs) because of malposition or lack of space is prevented from erupting into position. Along with the jaw degradation, more and more ITMs were found in the clinical examination.

The most popular are Winter's [2] and Pell and Gregory's [3] systems which classify the height of the mandible ITMs, the angulation of the second molar, the occlusal plane and the ascending mandibular ramus.

According to Samira [4] and Ahu [5], the ITMs incidence is $54.3 \%$ and $54.1 \%$ of young adults in Saudi and Turkish. The ITMs incidence is up to $68.6 \%$ of the Chinese population in Singapore [6]. Kruger [7] and Yuasa [8] had claimed that the incidence of mandibular ITMs are higher in females. Mandibular medial vertical ITMs are one of the ITMs classifications. Some studies have reported that the incidence of mandibular vertical ITMs accounted for $43.8 \%$ of the mandibular ITMs in China [9].

The extraction of mandibular ITMs is one of the most frequently performed procedures in oral surgery $[3,7,10]$. Generally, most of the surgeries are performed under local anesthesia in dental clinics $[3,8,11]$. The surgical removal of mandibular ITMs generally produces facial swelling, pain, and limited mouth opening [10], which affects the quality of life and restricts daily activities of the patient in the short term [12]. There are many factors that influence the postoperative outcome, but surgical procedure is one of the reasons behind this $[11,13,14,15,16,17]$. Many oral and maxillofacial surgeons have therefore put stress on better facial swelling, pain, and trismus control in patients who undergo ITMs extractions [18].

The extraction of mandibular vertical ITMs can be used on the bone removal procedures, and can also be used on the split-root procedures. Currently, there has not been a reported comparison on the dental root fracture, operative time and postoperative complications between the split-root procedures and the bone removal procedures in mandibular vertical ITMs extraction surgery.

The purpose of this study was to compare the differences of dental root fracture, operative time and possible postoperative complications between the split-root procedures and the bone removal procedures in mandibular vertical ITMs extraction surgeries, and to evaluate the advantages and disadvantages of the two procedures. This study will provide the best surgical procedure in mandibular vertical ITMs extraction surgery. 


\section{Material and Methods}

The present study received approval from the local Ethics Committee. The subjects were selected from a pool of patients admitted for Oral Surgery treatment between January 2015 and December 2015. A prospective study was implemented involving 30 healthy patients between 21 and 40 years old. All patients signed a statement of informed consent.

Inclusion Criteria:

- Male patients were scheduled for a bilateral surgical removal of symmetrically placed mandibular ITMs and without systemic disease.

- The ITMs had multiple dental roots in panoramic films.

- Panoramic radiographs were taken to ensure the similarity of the ITMs based on Winter's classification (only vertical positions were used) and the Pell \& Gregory classification (only class II -B were used) [2, 3].

- No any contraindications for oral surgery, no pericoronitis, and were not taking any medication longterm.

Thirty patients (60 mandibular vertical ITMs) were treated with autologous about control, and were randomly assigned to the experimental group or the control group. The experimental group received split-root procedures and the control group received bone removal procedures. A coin toss determined the surgery sequence procedure. The surgery interval was 3 weeks. The dental root fracture, operative time, facial swelling, pain and mouth opening were recorded.

Preoperatively, all patients orally took $150 \mathrm{mg}$ of Roxithromycin release capsules 30 minutes prior to surgery and used $10 \mathrm{ml}$ of $0.02 \%$ chlorhexidine for $2 \mathrm{~min}$. The same oral surgeon operated on each patient. A $1.0 \%$ povidoneiodine solution and a $0.02 \%$ chlorhexidine rinse were applied to the extra-oral and intra-oral antisepsis. The alveolar, lingual and long buccal nerve block technique was used for achieving effective anaethesia with $2.0 \%$ lidocaine with 1:200,000 epinephrine at the site of the surgery. The gums were given an " 1 " shaped incision and the mucoperiosteal flap was raised. When the Split-root group first with $45^{\circ}$ elevation turbines along the long axis of the ITMs cutting the mesial dental root and distal dental root apart. Then the mesial dental root was removed, and finally, the distal dental root was removed with the elevator. The bone removal group first with $45^{\circ}$ elevation turbines to remove the distal bone of the ITMs, then extract the third molars with elevator or dental pliers. All procedures were performed under constant irrigation with saline. Socket was cleaned after the tooth was removed. The 4-0 absorbable suture was used for hermetically suturing the mucoperiosteal flap. One vertical ITMs was removed on the first surgical visit and the contralateral vertical ITMs was removed two weeks later.

Post operative instructions included the following.

- Apply ice pack for 6 hrs after surgery. Practice a soft diet for 3 days. Strenuous exercise is prohibited for 3 days.

- $0.02 \%$ Chlorhexidine mouth rinse for one minute thrice daily after diet. Roxithromycin release capsules 150 $\mathrm{mg}$. Ornidazole $500 \mathrm{mg}$, twice a day for 3 days.
Ibuprofen Modify-release Capsules were also used as the rescue drug.

- Patients referral on 48 and 120 hrs after surgery.

Evaluation Criteria: The following variables were recorded.

Operative time:

The operation time was recorded from the start of the cutting of the gums at the site of the ITMs, until the suture at the surgical site was completed with a stopwatch.

Dental root fracture:

No dental root fracture was recorded 0 , breaking one dental root was recorded 1 , breaking two dental roots were recorded 2, and so on. If necessary, shoot apical film examination. [15]

Pain (VAS score):

A 10-level visual analog scale (VAS) was used for assessing patients' pain intensity (Fig. 1). The scale indicates an intensity range from no pain (0) to worst pain $(10)[15,19]$. On the 48th and 120th hours after surgery, the pain rating was evaluated. The patients were authorized to take analgesics (Ibuprofen Modify-release Capsules $300 \mathrm{mg}$ twice a day) in case of pain on the first day after surgery. The amount of the analgesia was recorded.

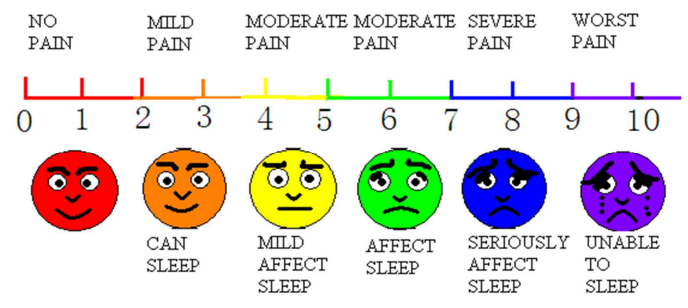

Fig. 1. VAS scale to evaluate pain.

Facial Swelling:

Facial swelling was measured by using facial following lines. The first line corresponded to the horizontal line (AB) joined from the tragus point (A) to the ipsilateral altercation point (B). Another vertical line (CD) was joined from the ipsilateral outer canthus point (C) of the eye to the mandibular angle point (D) (Fig. 2). It was measured with a thread and was then transferred on scale $[15,20]$. The average data of the differences from the postoperative and preoperative values was calculated.

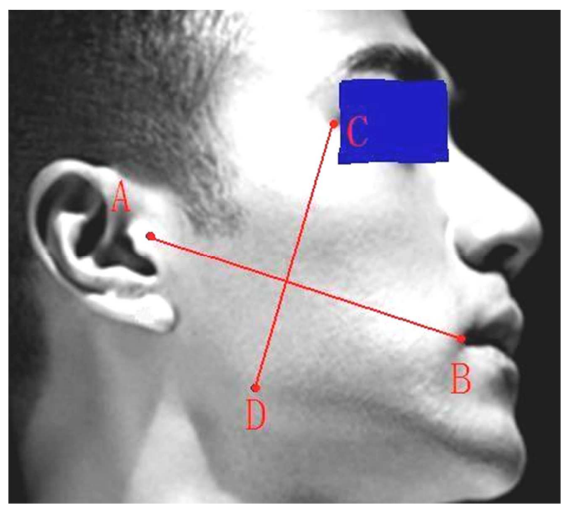

Fig. 2. Facial swelling measurement by joining the 2 lines $A B$ and $C D$. 
Facial measurements were taken both before surgery and on the $48^{\text {th }}$ and $120^{\text {th }}$ hour after surgery. Before surgery and postoperatively on the 48 and $120 \mathrm{hrs}$ take the facial measurement. The average data of the differences from the postoperative and preoperative values was calculated.

Mouth Opening:

Mouth opening was assessed by measuring the maximal interincisal distance (MID) both before surgery, and on the 48th and 120th hours after surgery. (Fig. 3). The average data of the differences from the postoperative and preoperative values was calculated.

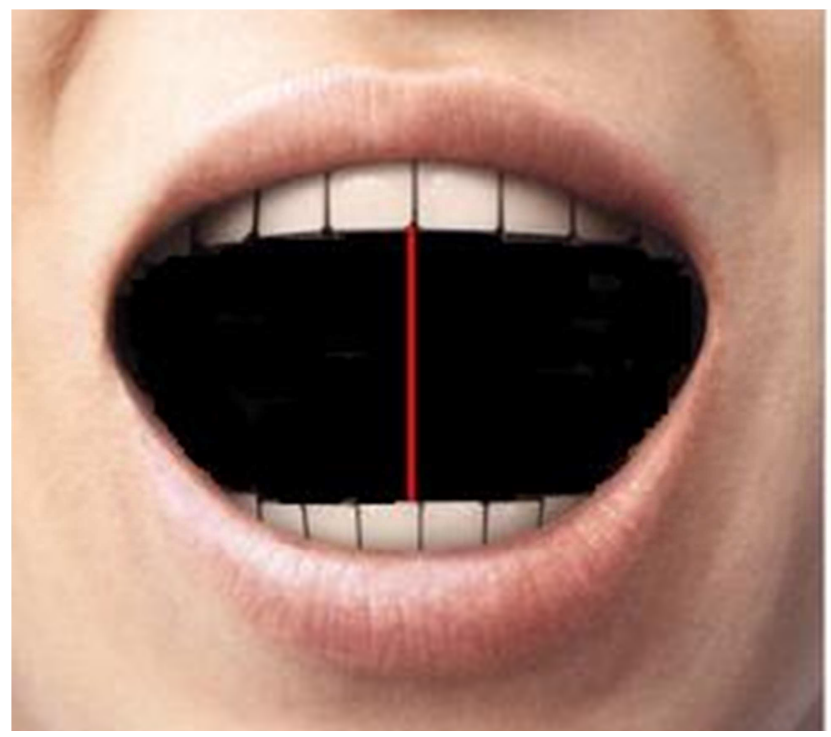

Fig. 3. The inter incisal distance between the upper and lower right central incisor was measured.

In order to avoid observer bias, all data was recorded by the same independent blinded investigator. The Statistical Package for Social Sciences (SPSS) 16.0 for Windows was used for analyzing and calculating data. The differences of mean operative time, root fracture, facial swelling, pain and trismus in the split-root group and bone removal group were analyzed using the paired samples T-test. A probability of less than 0.05 was considered significant for all tests.

\section{Results}

There was a total of 60 ITMs of the 30 male patients in the present study. [Mean age \pm standard deviation: $25.86 \pm 3.11$ years (range: 21 to 40 years). However, 4 cases of bone removal group because removal difficult to split-root procedure.

The statistical analysis revealed that the mean operative time of the split-root group was shorter than the bone removal group; there was a significant difference between the two groups $(\mathrm{P}<0.05)$. There were 5 cases of the dental root fracture in the split-root group, while the bone removal grouped yielded 13 cases. There was a significant difference between the two groups $(\mathrm{P}<0.05)$. (Table 1). The dental root fracture of split-root group was 5 cases and the bone removal group was 13 cases, there was significant difference between the two groups $(\mathrm{P}<0.05)$. (Table 1$)$.

Table 1. Comparison of the mean operative time and dental root fracture with two procedures.

\begin{tabular}{|c|c|c|c|}
\hline Groups & Cases & $\begin{array}{l}\text { Operative } \\
\text { time(min) }\end{array}$ & $\begin{array}{l}\text { Dental root } \\
\text { fracture }\end{array}$ \\
\hline Split-root group & 30 & $6.12 \pm 2.14$ & $0.1 \pm 0.24$ \\
\hline Bone removal group & 30 & $8.34 \pm 3.56$ & $0.26 \pm 0.64$ \\
\hline
\end{tabular}

The pain, facial swelling, and limited mouth opening of the split-root group was less severe than that of the bone removal group; the mean differences were significant ( $\mathrm{P}=0.01, \mathrm{P}=0.00$ and $\mathrm{P}=0.00$ respectively) on the 48 hours. After 120 hours, there was no significant difference of pain and facial swelling between the two groups. There was however a statistically significant difference $(\mathrm{P}<0.05)$ between the two groups on the 120th hour postoperatively, with the subjects in the bone removal group showing a smaller mouth opening when compared to the split-root group. (Table 2, Table 3 and Table 4).

Table 2. Comparison of the mean pain with the two procedures on the 48th and 120th hours.

\begin{tabular}{l|l|l|l}
\hline Groups & Cases & $\begin{array}{l}\mathbf{4 8} \text { hours after } \\
\text { surgery }\end{array}$ & $\begin{array}{l}\mathbf{1 2 0} \text { hours after } \\
\text { surgery }\end{array}$ \\
Split-root group & 30 & $2.42 \pm 2.54$ & $0.22 \pm 0.34$ \\
Bone removal group & 30 & $4.14 \pm 2.76$ & $0.28 \pm 0.32$ \\
\hline
\end{tabular}

Table 3. Comparison of the mean facial swelling with the two procedures on the 48th and 120th hours.

\begin{tabular}{lllll}
\hline Group & Cases & $\begin{array}{l}\text { 48 hours after surgery } \\
\text { The difference of AB }\end{array}$ & $\begin{array}{l}\text { The Difference of CD } \\
\text { The difference of AB }\end{array}$ & $\begin{array}{l}\text { The difference of CD } \\
\text { Split-root group }\end{array}$ \\
Bone removal group & 30 & $0.86 \pm 0.51$ & $0.95 \pm 0.46$ & $0.20 \pm 0.12$ \\
\hline
\end{tabular}

Table 4. Comparison of the mean mouth opening with the two procedures on the 48 and 120 hrs.

\begin{tabular}{llll}
\hline Groups & Cases & $\begin{array}{l}\mathbf{4 8} \text { hours after } \\
\text { surgery }\end{array}$ & $\begin{array}{l}\mathbf{1 2 0} \text { hours after } \\
\text { surgery }\end{array}$ \\
Split-root group & 30 & $2.25 \pm 1.04$ & $0.41 \pm 0.44$ \\
Bone removal group & 30 & $4.54 \pm 1.16$ & $0.78 \pm 0.52$ \\
\hline
\end{tabular}

The amount of Oral Ibuprofen Modify-release Capsules postoperatively in patients of the split-root group was less than that of the bone removal group; the mean difference was significant $(\mathrm{P}<0.05)$ (Table 5).

Table 5. Comparison of Oral Ibuprofen Modify-release Capsules with the two procedures after surgery.

\begin{tabular}{l|l|l}
\hline Groups & Cases & $\begin{array}{l}\text { Oral Ibuprofen Modify-release } \\
\text { Capsules (grams) }\end{array}$ \\
Split-root group & 30 & $0.45 \pm 0.44$ \\
Bone removal group & 30 & $0.80 \pm 0.73$ \\
\hline
\end{tabular}




\section{Discussion}

The mandibular ITMs are one of the most common oral surgery diseases [21]. The ITMs often cause pericoronitis, periodontitis, cysts or neoplasms, periapical abscess, and resorption of adjacent roots [20]. Thus, most ITMs need to be removed [14].

The surgical removal of mandibular ITMs generally produces facial swelling, pain and a limited mouth opening [10]. There are many factors that influence the postoperative outcome (such as patient age, gender, weight and dental factors) $[8,19,21,22,23,24]$. In order to reduce the impact of many factors of surgical complications in the extraction of ITMs, the inclusion criteria of these cases were male patients between 21 and 40 years old [mean age \pm standard deviation: $25.86 \pm 3.11]$ scheduled for the bilateral surgical removal of symmetrically placed mandibular ITMs, similar weight, no ethnic differences, no pericoronitis and were not taking any medication long-term in the present study. All data was recorded by the same independent blinded investigator. The methodology used in the present study was more specific to avoid bias and to improve the reliability of the results.

Some studies have reported that the incidence of mandibular vertical ITMs accounted for $43.8 \%$ of the mandibular ITMs in China [9]. We found that the removal of mandibular vertical ITMs with multiple dental roots can use the bone removal procedure and/or the split-root procedure. The principles of the two procedures are different. Bone removal procedure first with turbines to remove the distal bone of ITMs, then extract the third molars with elevator or dental pliers. However, split-root procedure first with turbines cutting tooth to the mesial dental root and distal dental root apart, the mesial dental root lose distal resistance, then remove the mesial dental root. Concurrently, the distal dental root lose mesial resistance, and finally remove the distal dental root with elevator or dental pliers. According to clinical observations, the surgical trauma, dental root fracture and postoperative complications of the split-root procedure were less than the bone removal procedure. The results of the present study are consistent with the clinical observations, which is in agreement with the findings reported by Ren-yi SUN [15].

The operative time and dental root fracture of the split-root procedure were less than the bone removal procedure in the present study, which related to the surgical accidents [15]. When extracted mandibular medial vertical ITMs applied the bone removal procedure, the operative time was shorter if the dental root had a small furcation. Reversely, the operative time was longer if the dental root had a big furcation. At the same time, the bone removal increased surgical trauma in addition. While the effect of dental root furcation in the splitroot procedure was less than bone removal procedure. Therefore, the operation time of the split-root procedure was short.

The pain, facial swelling, limited mouth opening and Oral Ibuprofen Modify- release Capsules of the split-root group was less severe than that of the bone removal group on the 48th hour postoperatively. This finding may be attributed to secondary postoperative hypersensitivity [17], which may be related to the longer operation time and surgical trauma $[10$, $13,14,15,22,25]$. After 120 hours, there was no significant difference of pain and facial swelling between the two groups. However, the bone removal group showed a smaller mouth opening compared to the split-root group, which may be related to the longer operation time, surgical trauma and jemporomandibular joint damage [10, 15, 19]. However, this issue needs to be investigated in further studies. In the present study, 8 cases of jemporomandibular joint damage were observed in the bone removal group, while only 2 cases of jemporomandibular joint damage were observed in the split-root group, which may be related to the larger force of using the elevator. After a reasonable treatment, 10 patients recovered after two weeks.

Although the postoperative complications of the splitroot procedure were less severe than that of the bone removal procedure, there are limitations in the split-root procedure. First, the split-root procedure is difficult if the dental root has a small and low furcation. It will be increased the surgery difficulty if the split-root fails. Second, the split-root procedure requires a long bur $(25 \mathrm{~mm})$, which is easy to damage the bone below the dental root furcation and the bone both sides of ITMs. This procedure required oral and maxillofacial surgeons to accurately determine the location of the alveolar bone. Finally, the mouth opening of patients was larger in the split-root group than the bone removal group [15].

According to the author's clinical experience, the bone removal procedure should be used if the dental root of the mandibular medial vertical ITMs has a small and low furcation. This method can improve the operation efficiency. The split-root procedure should be used if the dental root has a big furcation. This procedure can reduce surgical trauma and the difficulty of surgery operation.

\section{Conclusion}

Based on the findings of the present study, the operative time of the split-root procedure is shorter. The dental root fracture and postoperative complications of the split-root procedure were less common in the extraction of mandibular medial vertical ITMs with multiple dental roots. The shortterm outcomes of medial vertical impacted third molar operations (facial swelling, pain and mouth opening) differed depending on the surgical approach. However, due to the limitation of the present study, the results should be interpreted with caution. Further studies should be carried out by associations between operation time and jemporomandibular joint damage of mandibular ITMs extractions.

\section{Acknowledgements}

This study was supported by Stomatological Association of Inner Mongolia (IMSA-2015-C6). 


\section{References}

[1] Archer WH. Oral Surgery: A Step-By-Step Atlas of Operative Techniques. 4th ed. Philadelphia: W.B. Saunders Company, 1966: 507-510.

[2] de Santana Santos T, Calazans AC, Martins-Filho PR, Silva LC, de Oliveira ESED, Gomes AC. Evaluation of the muscle relaxant cyclobenzaprine after third-molar extraction. J Am Dent Assoc 2011, 142: 1154-1162.

[3] Akadiri OA, Fasola AO, Arotiba JT. Evaluation of Pederson index as an instrument for predicting difficulty of third molar surgical extraction. Niger Postgrad Med J 2009, 16: 105-108.

[4] Samira M. Al-Anqudi, Salim Al-Sudairy, Ahmed Al-Hosni, and Abdullah Al-Maniri. Prevalence and Pattern of Third Molar Impaction. Sultan Qaboos Univ Med J 2014, 14(3): e388-e392.

[5] Ahu Topkara, Zafer Sari. Investigation of third molar impaction in Turkish orthodontic patients: Prevalence, depth and angular positions. Eur J Dent, 2013, 7 (Suppl 1): S94S98.

[6] Quek SL, Tay CK, Tay KH, Toh SL, Lim KC. Pattern of third molar impaction in a Singapore Chinese population: a retrospective radiographic survey. Int J Oral Maxillafac Surg, 2003, 32: 548-552.

[7] Kruger E, Thomson WM, Konthasinghe P. Third molar outcomes from age 18 to 26: findings from a population-based New Zealand longitudinal study. Oral Surg Oral Med Oral Pathol Oral Radiol Endod, 2001, 92(2): 150-155.

[8] Yuasa H, Sugiura M. Clinical postoperative findings after removal of impacted mandibular third molars: prediction of postoperative facial swelling and pain based on preoperative variables. Br J Oral Maxillofac Surg, 2004, 42(3): 209-214.

[9] Zhi-yuan ZHANG, Guang-yan YU. Oral and Maxillofacial Surgery. Surgical removal of impacted tooth. 7th ed. Bei-jing: People's Health, 2013, 116.

[10] DA Ruta, E Bissias, S Ogston, GR Ogden. Assessing health outcomes after extraction of third molars: the postoperative symptoms severity (PoSSe) scale. Br J Oral Maxillofac Surg, 2000, 38: 480-487.

[11] Akadiri OA, Obiechina AE. Assessment of difficulty in third molar surgery -- a systematic review. J Oral Maxillofac Surg, 2009, 67: 771-774.

[12] GA Garcia, FH Sampedro, JH Rey, MG Torreira. Trismus and pain after removal of impacted lower third molars. J Oral Maxillofac Surg, 1997, 55: 1223-1226.

[13] M Chiapasco, L De Cicco, K Marroneh. Side effects and complications associated with third molar surgery. Oral Surg Oral Med Oral Pathol, 1993, 76: 412-420.
[14] V Lopes, R Mumenya, C Feinmann, M Harris. Third molar surgery: an audit of the indications for surgery, post operative complaints and patient satisfaction. Br J Oral Maxillofac Surg, 1995, 33: 33-35.

[15] Ren-yi SUN, Ping-juan FANG, Jin XIAO, Deng-feng LIU, Xing-qiao XU, Rong-dang HU.A comparative study of splitroot and medial resistance removal in extraction of medially impacted tooth. Shanghai Journal of Stomatology, 2012, 21: 344-349.

[16] Barbosa-Rebellato NL, Thomé AC, Costa-Maciel C, Oliveira J, Scariot R. Factors associated with complications of removal of third molars: a transversal study. Med Oral Patol Oral Cir Bucal, 2011, 16: e376-380.

[17] Gbotolorun OM, Arotiba GT, Ladeinde AL. Assessment of factors associated with surgical difficulty in impacted mandibular third molar extraction. J Oral Maxillofac Surg, 2007, 65: 1977-1983.

[18] Tiwana PS, Foy SP, Shugars DA, Marciani RD, Conrad SM, Phillips C. The impact of intravenous corticosteroids with third molar surgery in patients at high risk for delayed healthrelated quality of life and clinical recovery. J Oral Maxillofac Surg, 2005, 63: 55-62.

[19] Thiago de Santana-Santos, Jadson A. de Souza Santos, Paulo R.Martins- Filho, Luiz C. da Silva, Emanuel D. de Oliveira e Silva, Ana C. Gomes. Prediction of postoperative facial swelling, pain and trismus following third molar surgery based on preoperative variables. Med Oral Patol Oral Cir Bucal, Jan 2013, 18(1): e65-e70.

[20] Zandi M. Comparison of corticosteroids and rubber drain for reduction of sequelae after third molar surgery. $\mathrm{J}$ oral Maxillofac Surg 2008 12: 29-33.

[21] Renton T, Smeeton N, McGurk M. Factors predictive of difficulty of mandibular third molar surgery. Br Dent J, 2001 190: 607-610.

[22] Benediktsdóttir IS, Wenzel A, Petersen JK, Hintze H. Mandibular third molar removal: risk indicators for extended operation time, postoperative pain, and complications. Oral Surg Oral Med Oral Pathol Oral Radiol Endod, 2004, 97: 438-446.

[23] Yuasa H, Kawai T, Sugiura M. Classification of surgical difficulty in extracting impacted third molars. Br $\mathrm{J}$ Oral Maxillofac Surg, 2002, 40: 26-31.

[24] Garcia AG, Sampedro FG, Rey JG, Vila PG, Martin MS. PellGregory classification is unreliable as a predictor of difficulty in extracting impacted lower third molars. $\mathrm{Br} \mathrm{J}$ Oral Maxillofac Surg, 2000, 38: 585-587.

[25] Samir M, Abdul M, Seema A H, Mohammed Abid Z H.Mandibular third molar impactions in male adults: Relationship of Operative time and Types of impaction on inflammatory complications. J Int Oral Health, 2014, 6(2): 915. 